\section{Transport-reaction modeling of particulate organic matter and oxygen dynamics in riverbed sediments}

\author{
ERIC E RODEN ${ }^{1}$, ECENUR BULUR ${ }^{1}$, STEPHANIE A \\ NAPIERALSKI ${ }^{1}$, STEVEN P LOHEIDE III ${ }^{1}$, MATTHEW \\ GINDER-VOGEL ${ }^{1}$, CHRISTOPHER ZAHASKY ${ }^{1}$, EVAN \\ ARNTZEN $^{2}$ AND RUBY N GHOSH ${ }^{3}$ \\ ${ }^{1}$ University of Wisconsin-Madison \\ ${ }^{2}$ Pacific Northwest National Laboratory \\ ${ }^{3}$ Opti O2, LLC \\ Presenting Author: eroden@geology.wisc.edu
}

The hyporheic zone is a hot spot for coupled transport and biogeochemical reactions at the aquatic-terrestrial interface. This study deals with the riverbed of the Columbia river at the Hanford 300 Area study site in eastern Washington, USA, where fluctuations in river stage take place both naturally (seasonally) and in conjunction with hydroelectric power dam operations. These fluctuations create conditions conducive to the influx and transport of fine-grained POM (a biological colloid originating from the river water and/or in situ periphyton production), within near-surface riverbed sediments. Although a great deal is known about dissolved organic matter (DOM) transport and metabolism in hyporheic zone sediments, there is a paucity of quantitative information on POM dynamics and its influence on hyporheic zone biogeochemistry. We have developed a hydrobiogeochemical model capable of predicting the transport and metabolism of POM and its impact on dissolved oxygen (DO) distribution within the riverbed as influenced by periodic changes in river stage and fluid flow rate and direction. The model accounts for velocity-dependent POM filtration and reversible sorption of POM to the sediment matrix. A standard suite of POM metabolic pathways is depicted according to modified Monod kinetics, driven by first-order degradation of suspended and solid-associated POM, and of DOM produced during POM decay. The model predicted accumulation of fresh POM within the upper few $5 \mathrm{~cm}$ of the riverbed consistent with field POM trap deployments (Figure 1). Once sufficient surface POM accumulation takes place, an underlying zone of DO depletion develops as a consequence of variation in the rate of fluid exchange versus POM/DOM degradation (Figure 2A). The model predicts cyclic, hydrologically-driven variations in nearsurface DO that are consistent with the results of recent in situ time-resolved DO and fluid conductivity probe deployments in the upper $20 \mathrm{~cm}$ of Hanford 300 Area sediments (Figure 2B,C). Our results suggest a complex interplay between fluid flow rate/direction and DO distribution that has important implication for riverbed biogeochemical dynamics (e.g. redox zonation, $\mathrm{C}, \mathrm{N}$ and Fe cycling) as influenced by the relative intensity of POM input and the availability of oxygen and other electron acceptors for microbial metabolism.
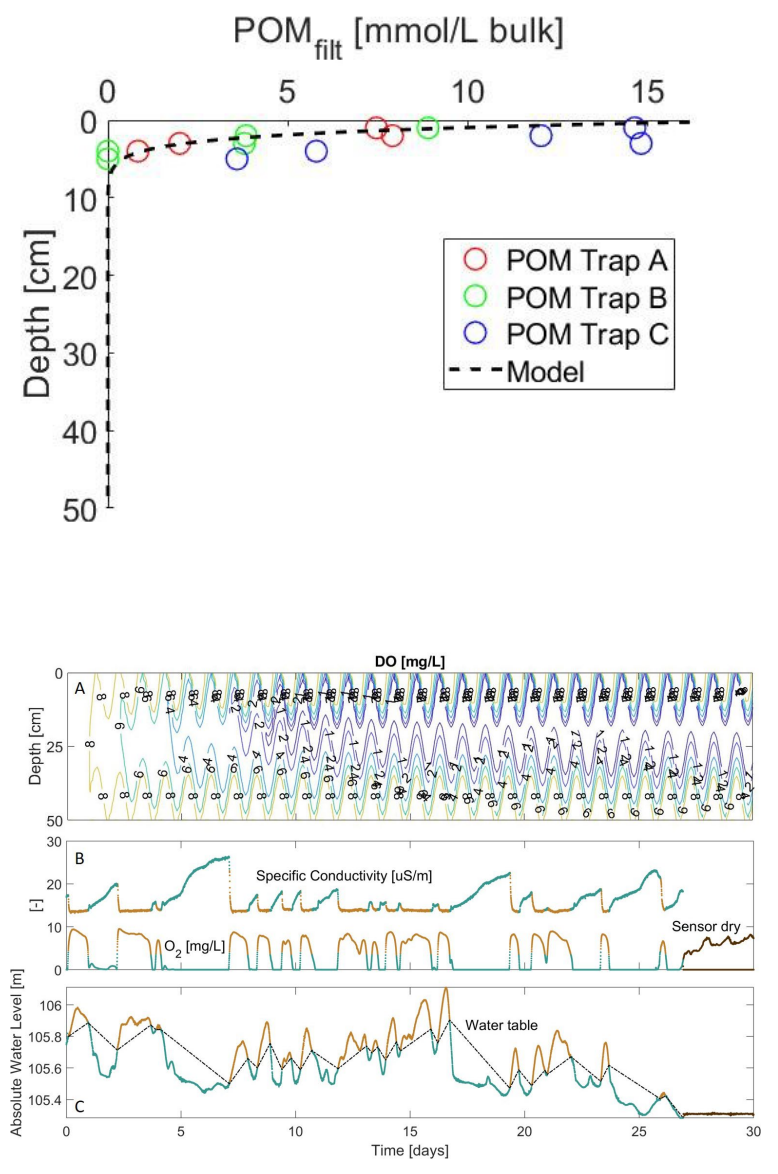